\title{
Clinically Approved Nanoparticle Imaging Agents
}

\author{
Avnesh S. Thakor*1, Jesse V. Jokerst*2, Pejman Ghanouni ${ }^{1}$, Jos L. Campbell ${ }^{1}$, Erik Mittra ${ }^{1}$, and Sanjiv S. Gambhir ${ }^{1}$ \\ ${ }^{1}$ Department of Radiology, Stanford University Medical Center, Stanford, California; and ${ }^{2}$ Department of Nano Engineering, \\ University of California-San Diego, San Diego, California
}

\begin{abstract}
Nanoparticles are a new class of imaging agent used for both anatomic and molecular imaging. Nanoparticle-based imaging exploits the signal intensity, stability, and biodistribution behavior of submicron-diameter molecular imaging agents. This review focuses on nanoparticles used in human medical imaging, with an emphasis on radionuclide imaging and MRI. Newer nanoparticle platforms are also discussed in relation to theranostic and multimodal uses.
\end{abstract}

Key Words: nanoparticles; medical imaging; molecular imaging; nanoparticle; imaging and diagnostics

J Nucl Med 2016; 57:1833-1837

DOI: 10.2967/jnumed.116.181362

\begin{abstract}
Medical imaging offers rapid, longitudinal, and noninvasive visualization of the interior of living subjects. There are two main approaches to medical imaging, the first being anatomic imaging, which provides information on gross structure, and the second being molecular or functional imaging, which provides information on physiology and cellular processes such as metabolism, protein expression, and DNA synthesis (1). Although exogenous imaging agents are optional for anatomic imaging (e.g., MRI or CT contrast medium agents, which help improve tissue contrast), they are virtually a requirement for molecular imaging, especially within the realm of nuclear medicine, for which radioisotopes are required for single-photon emission CT (SPECT) or PET.

The 3 main classes of imaging agents include small molecules, proteins, and nanoparticles. Most scans use small molecules, which are agents below 2,000 $\mathrm{kDa}$ and measure approximately $1 \mathrm{~nm}$ (e.g., ${ }^{18} \mathrm{~F}-\mathrm{FDG}$ for PET, iodinated small molecules for CT, and chelated gadolinium for MRI). Protein imaging agents, such as radiolabeled monoclonal antibodies, are less common but offer precise molecular information and are a growing area of research. Nanoparticles are a new and exciting class of imaging agent that can be used for both anatomic and molecular imaging.

Received Mar. 20, 2015; revision accepted Sep. 3, 2016.

For correspondence or reprints contact: Sanjiv S. Gambhir, Department of Radiology, James H. Clark Center, 318 Campus Dr., Stanford, CA 94305.

E-mail: sgambhir@stanford.edu

${ }^{*}$ Contributed equally to this work.

Published online Oct. 13, 2016.

COPYRIGHT (C 2016 by the Society of Nuclear Medicine and Molecular Imaging, Inc.
\end{abstract}

Their small size and unique properties (high ratio of surface area to volume) offer, first, intense and longitudinally stable imaging signals (quantum and $\mathrm{C}$ dots); second, different targeting strategies (passive targeting via the mononuclear phagocyte system or active targeting to specific molecular targets as a result of functionalization with ligands); third, high avidity (a large association constant brought about by the presence of multiple ligands per particle); fourth, theranostic capabilities (use for both diagnostic purposes, by generating an imaging signal, and therapeutic purposes, by delivering a drug payload); fifth, multimodal signal capabilities (detection of one nanoparticle by more than one imaging modality, making it suitable for deep tissue imaging, screening with MRI, and intraoperative guidance using superficial imaging with optical imaging); and sixth, multiplexing (detection of multiple different molecular targets simultaneously).

Although many of these features have been demonstrated only in animal models, there are several nanoparticle formulations that have been transitioned into clinical practice. This review focuses on these clinically available nanoparticles, which have been approved for use by the Food and Drug Administration (FDA).

\section{FDA-APPROVED NANOPARTICLE IMAGING AGENTS}

\section{Radionuclide Imaging}

Nuclear medicine has been using nanoparticles for many years and refers to them as colloids. Colloidal nanoparticles are made from a carrier platform, such as sulfur and stannous fluoride, with an imaging component, such as technetium. The most common radioisotope used for medical imaging is ${ }^{99 \mathrm{~m}} \mathrm{Tc}$, which is derived from the radiodecayed ${ }^{99}$ Mo isotope. ${ }^{99 \mathrm{~m}} \mathrm{Tc}$ has a half-life of $6 \mathrm{~h}$ before decaying to ${ }^{99} \mathrm{Tc}$ via a $140-\mathrm{keV} \gamma$-transition, making it ideal for $\gamma$ - and SPECT cameras (2). Sulfur colloid radioisotopes are the most commonly used carrier platform in the United States, with millions of doses prescribed since 1978. These radioisotopes are generated by reacting sodium pertechnetate $\left(\mathrm{Na}^{99} \mathrm{TcO}_{4}\right)$ with sodium thiosulfate in the presence of dilute acid and stabilizing gelatin. The product has a wide size range $(10-1,000 \mathrm{~nm})$, which is subsequently filtered to remove larger particles (Figs. 1A and B) (3). Similarly, stannous fluoride colloid radioisotopes $\left({ }^{99} \mathrm{~m} \mathrm{Tc}_{-} \mathrm{SnF}_{2}\right)$ are made by mixing aqueous sodium fluoride with a solution 


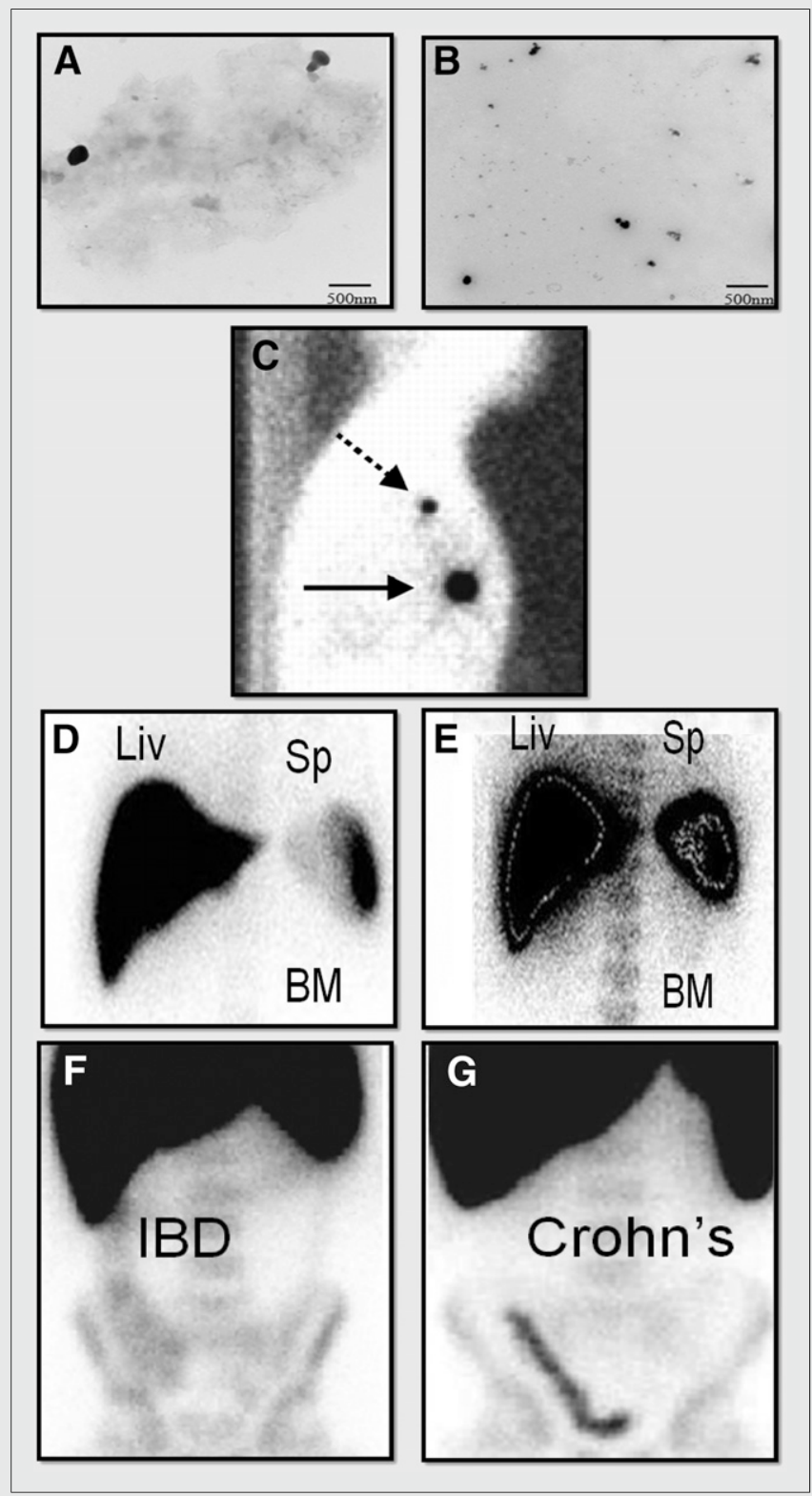

FIGURE 1. Clinical examples of nanoparticles used in radionuclide imaging. (A and $B$ ) Transmission electron micrographs of sulfur colloid before (A) and after (B) $0.2-\mu \mathrm{m}$ filtration. (Reprinted from (25).) (C) Use of sulfur colloid in breast lymphoscintigraphy. Here, original injection site is indicated by solid arrow and sentinel lymph node by dashed arrow. (Reprinted from (26).) (D and E) SPECT images illustrating colloid shift due to hepatic disease. Normal distribution of intravenously injected colloid is primarily to liver (Liv) (D), but in cases of liver damage, greater uptake is seen in spleen $(\mathrm{Sp})$ and spinal bone marrow $(\mathrm{BM})(\mathrm{E})$. (Reprinted with permission of (9).) (F and G) SPECT images showing use of $99 \mathrm{mTC}-$ $\mathrm{SnF}_{2}$ colloid nanoparticle-labeled lymphocytes to discriminate between irritable bowel disease $(F)$ and Crohn disease (G). These images were acquired $3 \mathrm{~h}$ after injection of contrast material. Increased inflammation in colon of Crohn patients leads to greater recruitment of labeled leukocytes after in vitro labeling and reinjection. (Reprinted from (10).)

of stannous fluoride in water. The product is then filtered to remove particles above $200 \mathrm{~nm}$ before being added to $\mathrm{Na}^{99 \mathrm{~m}} \mathrm{TcO}_{4}$ in saline (4). Additional carriers of $\mathrm{Na}^{99 \mathrm{~m}} \mathrm{TcO}_{4}$ include tin, rhenium, and polyvinylpyrrolidone; however, these constructs constitute a small fraction of the SPECT imaging workflow and are not considered further in this review (Table 1).

Sulfur colloids are used in the imaging algorithm for the staging of breast cancer and, more recently, melanoma $(5,6)$. After subcutaneous injection of less than $1 \mathrm{~mL}$ of ${ }^{99 \mathrm{~m}} \mathrm{Tc}$-sulfur colloid nanoparticles near the breast tumor, they are able to enter the lymphatic system to delineate the drainage pathway of the tumor and hence identify the primary or sentinel lymph node (Fig. 1C). This becomes important for surgical management of the disease, because surgeons can remove just selected clusters of lymph nodes instead of performing aggressive dissections and lymph node clearance, which can result in potentially harmful complications such as debilitating lymphedema (5). In 2010 , over 100,000 sentinel node mapping studies for breast cancer were performed. ${ }^{99 \mathrm{~m}} \mathrm{Tc}$-sulfur colloid nanoparticles can also be administered intraperitoneally for the assessment of diaphragmatic injury after thoracoabdominal trauma and for assessment of peritoneovenous shunt patency $(7,8)$. After intravenous injection of ${ }^{99 \mathrm{~m}} \mathrm{Tc}$-sulfur colloid, the nanoparticles accumulate in and are used to assess the organs of the mononuclear phagocyte system - the liver, spleen, and bone marrow. In general, the half-life of sulfur colloid in the circulation is only $2.5 \mathrm{~min}$, with $80 \%-90 \%$ of the radioactivity accumulating in the liver and the remainder in the spleen and bone marrow. However, liver conditions such as cirrhosis, metastasis, diabetes, trauma, or decreased blood flow can lead to increased bone marrow and splenic uptake of the nanoparticles, a process known as colloid shift (Figs. 1D and 1E) (9).

White blood cells can also be radiolabeled with ${ }^{99 \mathrm{~m} T c-}$ $\mathrm{SnF}_{2}$ colloid nanoparticles for the assessment of infection and inflammation. For this application, whole blood is removed and the buffy coat containing leukocytes is isolated and mixed with ${ }^{99 \mathrm{~m}} \mathrm{Tc}-\mathrm{SnF}_{2}$. As the blood is not fractionated and stressed, leukocytes will naturally phagocytize and take up the colloidal nanoparticles, thereby becoming radiolabeled. These radiolabeled leukocytes can be tracked using SPECT after their injection back into the patient's circulation, and since they still behave like normal leukocytes, they will travel to sites of infection or inflammation within $24 \mathrm{~h}$ while producing a signal that is detected using SPECT. Applications for ${ }^{99} \mathrm{~m} \mathrm{Tc}-\mathrm{SnF}_{2}$ colloid nanoparticles include assessment of fevers of unknown origin, detection of inflammatory bowel disease, and differentiation of inflammatory bowel disease from irritable bowel disease (Figs. $1 \mathrm{~F}$ and $1 \mathrm{G})(4,10)$.

Albumin colloidal nanoparticles are an alternative platform and in Europe are used more than sulfur colloid nanoparticles. Their main advantages include a higher quantitative labeling yield and a smaller particle size (mean diameter of $30 \mathrm{~nm}$, with most nanoparticles being below 80 $\mathrm{nm}$ ). Their smaller size also allows for quicker migration through the lymphatic system but still adequate retention within the sentinel lymph node, thereby allowing their use 
TABLE 1

Clinically Approved Nanoparticles

\begin{tabular}{|c|c|c|c|c|c|}
\hline Type & Size $(n m)$ & Agent & Modality & Indication & Trade name \\
\hline Sulfur colloid & $100-300$ & 99mTc & SPECT & $\begin{array}{l}\text { Lymphoscintigraphy, bone marrow, } \\
\text { gastrointestinal, liver and spleen }\end{array}$ & Technecoll (US) \\
\hline Albumin colloid & $6-80$ & 99mTc & SPECT & $\begin{array}{l}\text { Lymphoscintigraphy, inflammation } \\
\text { imaging, melanoma, prostate }\end{array}$ & Nanocoll (EU) \\
\hline $\mathrm{SnF}_{2}$ colloid & $<200$ & 99mTc & SPECT & $\begin{array}{l}\text { Lymphoscintigraphy, gastrointestinal, } \\
\text { liver and spleen }\end{array}$ & Hepatate (France) \\
\hline $\mathrm{Re}_{2} \mathrm{~S}_{7}$ colloid & $10-70$ & 99mTc & SPECT & $\begin{array}{l}\text { Lymphoscintigraphy, gastrointestinal, } \\
\text { melanoma, prostate }\end{array}$ & Nanocis (EU) \\
\hline Albumin colloid & $100-600$ & 99mTc & SPECT & Lymphoscintigraphy of breast & Senti-Scint \\
\hline $\begin{array}{l}\text { Dextran-coated iron } \\
\text { oxide (ferumoxide) }\end{array}$ & 80-150 & $\begin{array}{l}\mathrm{Fe}^{2+} \mathrm{Fe}^{3+}{ }_{2} \mathrm{O}_{4} \\
\left(\mathrm{Fe}^{3+} \mathrm{Fe}^{2+}{ }_{2}\right) \mathrm{O}_{4}\end{array}$ & MRI & $\begin{array}{l}\text { Mononuclear phagocyte system } \\
\text { imaging, cellular labeling. }\end{array}$ & $\begin{array}{l}\text { Feridex (US), } \\
\text { Endorem (Britain) }\end{array}$ \\
\hline $\begin{array}{l}\text { Dextran-coated iron } \\
\text { oxide (ferumoxtran) }\end{array}$ & $20-40$ & $\begin{array}{l}\mathrm{Fe}^{2+} \mathrm{Fe}^{3+}{ }_{2} \mathrm{O}_{4} \\
\left(\mathrm{Fe}^{3+} \mathrm{Fe}^{2+}{ }_{2}\right) \mathrm{O}_{4}\end{array}$ & MRI & $\begin{array}{l}\text { Lymph node imaging, } \\
\text { perfusion imaging }\end{array}$ & $\begin{array}{l}\text { Sinerem (EU), } \\
\quad \text { Combidex (US) }\end{array}$ \\
\hline $\begin{array}{l}\text { Carboxydextran-coated iron } \\
\text { oxide (ferucarbotran) }\end{array}$ & 60 & $\gamma-\mathrm{Fe}_{2} \mathrm{O}_{3}$ & MRI & $\begin{array}{l}\text { Hepatocellular carcinoma, } \\
\text { cell labeling }\end{array}$ & $\begin{array}{r}\text { Resovist (US, EU), } \\
\text { Cliavist (France) }\end{array}$ \\
\hline $\begin{array}{l}\text { Polyglucose sorbitol } \\
\text { carboxymethylether-coated } \\
\text { iron oxide (ferumoxytol) }\end{array}$ & $17-30$ & $\gamma-\mathrm{Fe}_{2} \mathrm{O}_{3}$ & MRI & $\begin{array}{l}\text { Iron-deficiency anemia, off-label } \\
\text { uses in imaging }\end{array}$ & Faraheme (US) \\
\hline
\end{tabular}

in lymphoscintigraphy. In addition, as albumin localizes 5 -fold more than sulfur colloid in the bone marrow after intravenous injection, these nanoparticles are useful for bone marrow imaging (11).

\section{MRI}

MRI has high spatial resolution and excellent soft-tissue contrast, even in the absence of injected contrast medium agents. Nevertheless, there are two main classes of MRI contrast medium agent that better define anatomy and pathology not optimally imaged with modulation of radiofrequency pulse sequences alone: the first is gadolinium-containing small molecules, which will not be considered further here but have been reviewed elsewhere (12), and the second is superparamagnetic iron oxide nanoparticles (SPIONs). Whereas gadolinium shortens the $\mathrm{T} 1$ relaxation time of protons inside tissues, the iron component in SPIONs has a large magnetic moment resulting in local magnetic field inhomogeneities that reduce the MRI signal intensities on T2- and T2*-weighted images.

SPIONs are produced through several routes, including aqueous coprecipitation, thermal decomposition, and a sol-gel reaction. In general, SPIONs range in size from 1 to $100 \mathrm{~nm}$ and must be coated with polymers, such as polyethylene glycol or dextran, to avoid aggregation and increase colloidal stability (13). In the laboratory, SPIONs have also been packaged in viral vectors, micelles, liposomes, dendrimers, or emulsions. Additional moieties have also been added to SPIONs to enable organ, lymph node, or tumor targeting. The biodistribution of SPIONs is highly dependent on the administration route and the surface charge of the particles in question. The nanoparticles clear by 3-7 wk after intravascular administration, with the highest spike in liver uptake occurring in the first $6 \mathrm{~h}$. The negative surface charges on ferumoxides and ferucarbotran $(-30 \mathrm{mV})$ increase hepatic uptake, whereas the nearly neutral charge on ferumoxtran increases blood half-life. The relatively long intravascular residence time of SPIONs allows for imaging to be performed hours or even days after injection.

After their intracellular uptake, SPIONs are metabolized in the lysosomes into a soluble nonsuperparamagnetic form of iron. This iron is then taken up into the normal iron metabolism pathways of the body and used in the production of hemoglobin and transferrin, thereby becoming part of the normal iron pool. Increased serum iron levels can induce mild oxidative stress, but this occurs only after repeated or high doses; there are no direct links to chronic or acute negative effects. The most common frequently reported adverse events of SPIONs are back pain and flushing, which occur in $4 \%$ and $2 \%$, respectively, of the population. Concerns about anaphylactic reactions also limit use in the clinic.

After intravenous injection in patients, SPIONs are removed from the circulation by the mononuclear phagocyte system, with approximately $80 \%$ removed by the Kupffer cells of the liver. In view of this fact, and the fact that liver tumors generally do not contain Kupffer cells, SPIONs were initially used clinically for hepatocellular carcinoma imaging and for the evaluation and differentiation of dysplastic nodules. Normal liver parenchymal tissue accumulates SPIONs, resulting in a loss of signal intensity, but tumor tissue within the liver or lymph nodes does not accumulate SPIONs, resulting in a high signal intensity (14). Research using SPIONs has demonstrated several other potential applications, including imaging of lymph nodes (Fig. 2), longitudinal tracking of stem cells, 


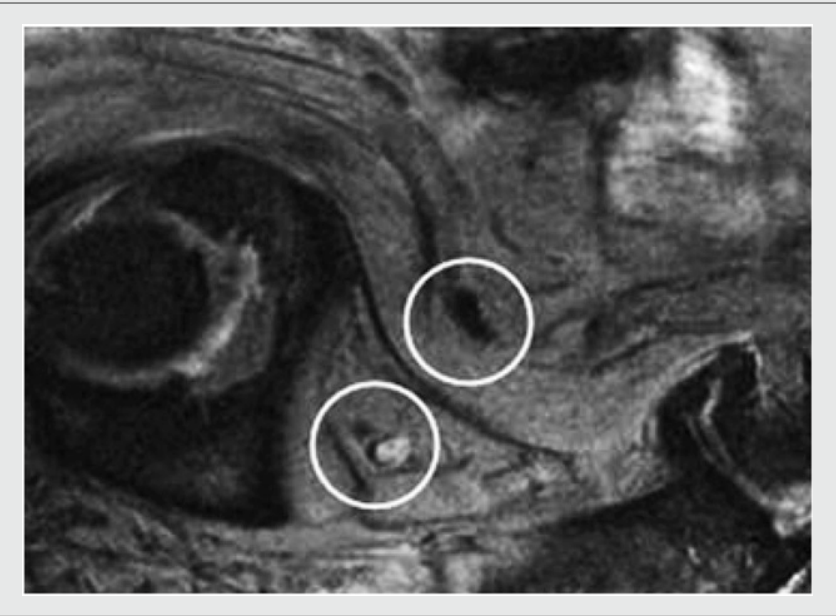

FIGURE 2. Clinical example of SPIONs used in MRI. Prostate cancer patient was injected with SPIONs and imaged $24 \mathrm{~h}$ later. Oblique sagittal T2*-weighted gradient-echo MR image shows normal lymph node as black (top) but metastatic lymph node as hyperintense (bottom) because it does not incorporate as many SPIONs. Without image guidance, this positive node would be excluded from pelvic lymph node dissection. (Reprinted with permission of (27).)

delineation of vascular pathways, imaging of cell surface reporters, and imaging of pancreatic islet inflammation in type $1 \mathrm{~A}$ diabetes $(15,16)$. Perhaps one of the most exciting uses of SPIONs is stem cell tracking, in which it has helped answer basic questions about stem cell numbers, engraftment, and postadministration location (17). One potential limitation of this application is that macrophages can encapsulate free SPIONs from dead stem cells and erroneously report a signal. Despite all these promising clinical applications, the previous FDA-approved clinical preparations of SPIONs used in medical imaging are no longer available because of concerns about toxicity and fatal anaphylactic reactions.

Currently, ferumoxytol is the only FDA-approved SPION and is used for the treatment of iron-deficiency anemia in patients with chronic kidney disease. However, ferumoxytol is also being used off-label as an MRI angiography agent in patients with renal failure who cannot be given gadolinium and in clinical trials for the characterization and mapping of metastatic lymph nodes and hepatic masses. The advantages of ferumoxytol include its size relative to other SPION formulations $(<40 \mathrm{~nm})$ and its long circulating half-life $(\sim 15 \mathrm{~h})$.

\section{FUTURE DIRECTIONS}

In addition to the development of new nanoparticle platforms that can be used for diagnostic purposes (Table 2), exciting advances in theranostic nanoparticle constructions are taking place (18). These nanoparticles can be used for both diagnostic (imaging) and therapeutic (drug delivery) applications, thereby potentially acting as a one-stop shop for patients. An example is doxorubicinloaded ferumoxytol nanoparticles, which can generate a signal that can be monitored with MRI while also carrying a drug payload to treat the cancerous tissue (19). Another area of development is multimodal nanoparticles, which can be detected by more than one imaging modality. This ability is advantageous as the same nanoparticle can then be used for both disease staging (e.g., deep tissue assessment with MRI or whole-body assessment with PET/ SPECT) and guidance of surgical resection (e.g., the use of real-time optical imaging to delineate surgical margins). An example application, which is being used to target human melanoma models, is a multimodal silica nanoparticle that contains a radioisotope detectable by PET along with a

TABLE 2

Clinical Trials Using Nanoparticles

\begin{tabular}{|c|c|c|c|c|c|}
\hline Type & Size $(n m)$ & Agent and modality & Motivation & Indication & Trial \\
\hline Sulfur colloid & $<220$ & 99mTc, SPECT & $\begin{array}{l}\text { Map lymph nodes during } \\
\text { rectal surgery }\end{array}$ & Colon cancer & NCT02112240 \\
\hline Sulfur colloid & $<220$ & 99mTc, SPECT & $\begin{array}{l}\text { Raise } \mathrm{pH} \text { of contrast agent } \\
\text { to minimize pain }\end{array}$ & Cancer & NCT01660412 \\
\hline Sulfur colloid & $<220$ & 99mTc, SPECT & $\begin{array}{l}\text { Map lymph nodes during } \\
\text { rectal surgery }\end{array}$ & $\begin{array}{l}\text { Head and throat } \\
\text { cancer }\end{array}$ & NCT00012168 \\
\hline Gold & 150 & $\begin{array}{l}\text { Nanoshell, } \\
\text { photothermal }\end{array}$ & $\begin{array}{l}\text { Increase local heating better } \\
\text { than by laser alone }\end{array}$ & $\begin{array}{l}\text { Head and neck } \\
\text { cancer }\end{array}$ & NCT00848042 \\
\hline Silica & $3-10$ & $\begin{array}{l}{ }^{124} \text { I and Cy5, PET } \\
\text { and optical }\end{array}$ & Define sentinel lymph nodes & Melanoma & NCT01266096 \\
\hline Iron oxide & $17-30$ & Ferumoxytol, MRI & $\begin{array}{l}\text { Monitor response to } \\
\text { bevacizumab therapy }\end{array}$ & Glioma & NCT00769093 \\
\hline Iron oxide & $17-30$ & Ferumoxytol, MRI & $\begin{array}{l}\text { Localize lymph node } \\
\text { metastases }\end{array}$ & Pancreatic cancer & NCT00920023 \\
\hline Iron oxide & $80-150$ & Ferumoxide, MRI & $\begin{array}{l}\text { Identify presence of } \\
\text { implanted stem cells }\end{array}$ & Inflammation & NCT01169935 \\
\hline Iron oxide & $17-30$ & Ferumoxytol, MRI & $\begin{array}{l}\text { Detect recent myocardial } \\
\text { infarction }\end{array}$ & Myocardial infarction & NCT01995799 \\
\hline
\end{tabular}


dye detectable by deep-red or near-infrared optical imaging (20). Another example is the combination of a radioactive colloidal nanoparticle, which permits preoperative planning, with a near-infrared fluorophore (indocyanine green) for intraoperative localization. The combination of indocyanine green with a ${ }^{99 \mathrm{~m}} \mathrm{Tc}$-radiolabeled nanocolloid has shown considerable clinical promise, with accurate preoperative and intraoperative detection of sentinel lymph nodes in patients with breast cancer (21), penile cancer (22), oral cancer (23), or endometrial or cervical cancer (24).

\section{CONCLUSION}

Nanoparticles hold great promise for both preclinical and clinical imaging. Although the potential applications seem endless in the laboratory setting, only a small percentage of nanoparticle applications has been translated into the clinics. The FDA, which approves imaging agents for clinical use in the United States, will allow use of nanoparticles on patients only if there are data demonstrating safety and efficacy. The safety parameters include data on pharmacology, absorption, distribution, metabolism, excretion, toxicity, chemistry, manufacturing, and controls, whereas the efficacy parameters include demonstration of clinical improvement relative to the current standard of care. Hence, careful nanoparticle design and extensive toxicity studies will help facilitate the clinical translation of new nanoparticles that have unique advantages over conventional imaging agents.

\section{DISCLOSURE}

Dr. Jokerst receives funding from R00 HL117048; Dr. Gambhir, from NIH grants CA119367 and CA114747; and Dr. Campbell, from a Victorian Postdoctoral Research Fellowship. Dr. Gambhir declares the following industrial affiliations: Bracco Diagnostics, Cellsight Technologies, Endra, Gamma Medica, General Electric, ImaginAb, Ninepoint Medical, Philips, RefleXion Medical, RioImaging, Siemens Medical, Spectrum Dynamics, Vave, and Visualsonics. No other potential conflict of interest relevant to this article was reported.

\section{REFERENCES}

1. Massoud TF, Gambhir SS. Integrating noninvasive molecular imaging into molecular medicine: an evolving paradigm. Trends Mol Med. 2007;13:183-191.

2. Banerjee S, Pillai MR, Ramamoorthy N. Evolution of Tc-99m in diagnostic radiopharmaceuticals. Semin Nucl Med. 2001;31:260-277.

3. Loveless VS, Surdock CP, Bhattacharjee H. Evaluation of zeta-potential and particle size of technetium ${ }^{99 \mathrm{~m}} \mathrm{Tc}$-sulfur colloid subsequent to the addition of lidocaine and sodium bicarbonate. J Nucl Med Technol. 2010;38:49-52.
4. Tsopelas C. The radiopharmaceutical chemistry of ${ }^{99 \mathrm{~m}} \mathrm{Tc}$-tin fluoride colloidlabeled-leukocytes. Q J Nucl Med Mol Imaging. 2005;49:319-324.

5. Newman EA, Newman LA. Lymphatic mapping techniques and sentinel lymph node biopsy in breast cancer. Surg Clin North Am. 2007;87:353-364.

6. Dengel LT, More MJ, Judy PG, et al. Intraoperative imaging guidance for sentinel node biopsy in melanoma using a mobile gamma camera. Ann Surg. 2011;253:774-778.

7. Williamson BR, Lambert MJ III, Teates CD, Bray ST, Wakefield JA. Patency evaluation of a LeVeen shunt using ${ }^{99 m}$ Tc-sulfur colloid. Clin Nucl Med. 1978;3:343-345.

8. May AK, Moore MM. Diagnosis of blunt rupture of the right hemidiaphragm by technetium scan. Am Surg. 1999;65:761-765.

9. Chakraborty D, Sunil HV, Mittal BR, Bhattacharya A, Singh B, Chawla Y. Role of Tc99m sulfur colloid scintigraphy in differentiating non-cirrhotic portal fibrosis from cirrhosis liver. Indian J Nucl Med. 2010;25:139-142.

10. Hughes DK. Nuclear medicine and infection detection: the relative effectiveness of imaging with ${ }^{111} \mathrm{In}$-oxine-, ${ }^{99 \mathrm{~m}} \mathrm{Tc}$-HMPAO-, and ${ }^{99 \mathrm{~m}} \mathrm{Tc}$-stannous fluoride colloidlabeled leukocytes and with ${ }^{67}$ Ga-citrate. J Nucl Med Technol. 2003;31:196-201.

11. Axelsson B, Kalin B, Von Krusenstierna S, Jacobsson H. Comparison of In-111 granulocytes and Tc-99m albumin colloid for bone marrow scintigraphy by the use of quantitative SPECT imaging. Clin Nucl Med. 1990;15:473-479.

12. Bellin M-F. MR contrast agents, the old and the new. Eur J Radiol. 2006;60:314-323.

13. Tong L, Zhao M, Zhu S, Chen J. Synthesis and application of superparamagnetic iron oxide nanoparticles in targeted therapy and imaging of cancer. Front Med. 2011;5:379-387.

14. Li YW, Chen ZG, Wang JC, Zhang ZM. Superparamagnetic iron oxide-enhanced magnetic resonance imaging for focal hepatic lesions: systematic review and meta-analysis. World J Gastroenterol. 2015;21:4334-4344.

15. Gaglia JL, Guimaraes AR, Harisinghani M, et al. Noninvasive imaging of pancreatic islet inflammation in type $1 \mathrm{~A}$ diabetes patients. $J$ Clin Invest. 2011;121:442-445.

16. Artemov D, Mori N, Okollie B, Bhujwalla Z. MR molecular imaging of the Her $2 /$ neu receptor in breast cancer cells using targeted iron oxide nanoparticles. Magn Reson Med. 2003;49:403-408.

17. Cromer Berman SM, Walczak P, Bulte JW. Tracking stem cells using magnetic nanoparticles. Wiley Interdiscip Rev Nanomed Nanobiotechnol. 2011;3:343-355.

18. Thakor AS, Gambhir SS. Nanooncology: the future of cancer diagnosis and therapy. CA Cancer J Clin. 2013;63:395-418.

19. Kaittanis C, Shaffer TM, Ogirala A, et al. Environment-responsive nanophores for therapy and treatment monitoring via molecular MRI quenching. Nat Commun. 2014;5:3384.

20. Benezra M, Penate-Medina O, Zanzonico PB, et al. Multimodal silica nanoparticles are effective cancer-targeted probes in a model of human melanoma. J Clin Invest. 2011;121:2768-2780.

21. Schaafsma BE, Verbeek FP, Rietbergen DD, et al. Clinical trial of combined radio- and fluorescence-guided sentinel lymph node biopsy in breast cancer. $\mathrm{Br} \mathrm{J}$ Surg. 2013;100:1037-1044.

22. Markuszewski M, Polom W, Cytawa W, Czapiewski P, Lass P, Matuszewski M. Comparison of real-time fluorescent indocyanine green and ${ }^{99 \mathrm{~m}} \mathrm{Tc}$-nanocolloid radiotracer navigation in sentinel lymph node biopsy of penile cancer. Clin Genitourin Cancer. 2015;13:574-580.

23. Murase R, Tanaka H, Hamakawa T, et al. Double sentinel lymph node mapping with indocyanine green and $99 \mathrm{~m}$-technetium-tin colloid in oral squamous cell carcinoma. Int J Oral Maxillofac Surg. 2015;44:1212-1217.

24. Buda A, Crivellaro C, Elisei F, et al. Impact of indocyanine green for sentinel lymph node mapping in early stage endometrial and cervical cancer: comparison with conventional radiotracer ${ }^{99 m}$ Tc or blue dye. Ann Surg Oncol. 2016;23:2183-2191.

25. Hegseth KM, Warren AM, Hung JC, Mosman EA. Evaluation of compatibility and stability of filtered ${ }^{99 \mathrm{~m}} \mathrm{Tc}$-sulfur colloid when combined with fluorescent indocyanine green dye. J Nucl Med Technol. 2012;40:194-197.

26. Pandit-Taskar N, Dauer LT, Montgomery L, St Germain J, Zanzonico PB, Divgi CR. Organ and fetal absorbed dose estimates from ${ }^{99 \mathrm{~m}} \mathrm{Tc}$-sulfur colloid lymphoscintigraphy and sentinel node localization in breast cancer patients. $J$ Nucl Med. 2006;47:1202-1208.

27. Heesakkers RA, Jager GJ, Hövels AM, et al. Prostate cancer: detection of lymph node metastases outside routine surgical area with ferumoxtran-10-enhanced MR imaging Radiology. 2009;251:408-414. 